\title{
Prenatal exposure to Benzo[a]pyrene causes learning and memory impairment and loss of neurons in hippocampus during development of wistar rats
}

\begin{abstract}
Animal studies demonstrate that exposure to benzo[a]pyrene, $(\mathrm{B}[\mathrm{a}] \mathrm{P})$ is associated with developmental neurotoxicity. The neurotoxicity of $\mathrm{B}[\mathrm{a}] \mathrm{P}$ is proposed to arise from the genotoxicity leading to neuronal cell death. Hence, gestational exposure to $\mathrm{B}[\mathrm{a}] \mathrm{P}$ during foetal development is thought to affect the adult behaviour. To explore this, in the present study the neurotoxic effects of B[a]P dosage (thrice, $300 \mu \mathrm{g} / \mathrm{kg} / \mathrm{BW} /$ day, each) after prenatal exposure were investigated. The pregnant Wistar rats were administered with $\mathrm{B}[\mathrm{a}] \mathrm{P}$ by intraperitonial (i.p.) from gestational days (GD14-17) with control group (i.e., $<0.1 \%$ DMSO) and a separate group of rats without any treatment taken as naive group. Behavior was assessed in the offspring at 6 weeks of age by using T-maze test and novel object recognition test. The histopathological analysis was carried out by haematoxylin and eosin (H\&E) staining method. A significant increase in the time spent in left arm, and decreased percentage of spontaneous exploration was observed in $\mathrm{B}[\mathrm{a}] \mathrm{P}$ treated groups in comparison to naïve and control. Further, time taken to reach near the novel object was significantly decreased, with significant increase in spontaneous exploration time in the $\mathrm{B}[\mathrm{a}] \mathrm{P}$ treated Wistar rats suggesting that gestational exposure impairs learning and memory as well as explorative behavior of rats. Cytomorphometry analysis of hippocampus showed significant loss in number of neurons in $\mathrm{B}[\mathrm{a}] \mathrm{P}$ treated group as compared to naive and control. Taken together, these findings showed during development gestational $\mathrm{B}[\mathrm{a}] \mathrm{P}$ exposure exerts memory deficit at adulthood and neuronal loss in hippocampus indicating its influences on adolescence behavior of the next generation.
\end{abstract}

Keywords: benzo[a]pyrene, gestation, learning and memory, neuronal loss
Volume 4 Issue 4 - 2019

\author{
Lipsa Das, Manorama Patri \\ Department of Zoology, Ravenshaw University, India
}

Correspondence: Manorama Patri, Neurobiology Laboratory, Department of Zoology, School of Life Sciences, Ravenshaw University, Cuttack-753003, Odisha, India, Tel 8763642486, Emailmpatri@ravenshawuniversity.ac.in

Received: June 27, 2019 | Published: July 08, 2019

\section{Introduction}

Exposure to environmental contaminants poses a significant threat to normal growth and differentiation of the developing brain. ${ }^{1}$ As a member of the polycyclic aromatic hydrocarbon (PAH) family, B[a] $\mathrm{P}$, is ubiquitous throughout the environment and is derived from the incomplete combustion of organic matter. ${ }^{2}$ It is known for its neurotoxic potential causing neurobehavioral alterations in animal models, ${ }^{3}$ and its metabolites can reach the brain tissues by crossing the blood-brain barrier and thereby gains direct access to the central nervous system. ${ }^{3-6}$ Accumulating evidence indicates that hippocampus is particularly important for spatial learning and memory, ${ }^{7}$ morphological changes occur during pregnancy, the postpartum period, and after weaning. However, in the present scenario very little is known about the mechanism of action and effects of these neurotoxicants on animals' model inducing persistent cognitive dysfunction of offspring during early-life to result in diseased phenotypes in later-life. Although a various mode of administration were known an intraperitonial $\mathrm{B}[\mathrm{a}]$ $\mathrm{P}$ administration during early gestation and the toxic insults induced by these neurotoxicants developing rat brain during postnatal development quite uncertain.

Recently, we demonstrated that sub-acute exposure to $\mathrm{B}[\mathrm{a}] \mathrm{P}(0.02$ and $0.2 \mathrm{mg} / \mathrm{kg} \mathrm{BW}$ ) in adult mice induced impairment of short-term and spatial memory. ${ }^{8}$ Epidemiological evidences regarding humans has shown prenatal exposure of $\mathrm{B}[\mathrm{a}] \mathrm{P}$ to the foetus adversely affects foetal development, resulting in low birth weight and reduced head circumference, as well as neurobehavioral deficits in the offspring. Due to mining activities and combustion of coal the elevated levels of environmental PAHs were found in children exposed in utero showing learning and memory disorders. ${ }^{9}$ Similarly, short-term memory loss were found in coke-production plant workers at Poland with developed neurotic syndromes depending on the level of exposure to $\mathrm{B}[\mathrm{a}] \mathrm{P} .{ }^{10}$ Prenatal or sub-acute exposure to B [a]P have reported robust neurotoxic effects resulting from exposure to polycyclic aromatic hydrocarbons on learning and memory mechanisms in rodent models (assessed by Y-maze, fixed-ratio operant conditioning, 2-lever reversal conditioning and Morris water maze performance). ${ }^{8,11}$ Gestational exposure to $\mathrm{B}[\mathrm{a}] \mathrm{P}$ aerosol attenuated the capacity for long-term potentiation and reduced learning and memory abilities in the F1 generation. ${ }^{11}$ Recent studies also showed that $\mathrm{B}[\mathrm{a}] \mathrm{P}$ adversely affects a number of fetal developmental indices such as low birth weight, ${ }^{12-14}$ impaired learning and memory, ${ }^{15,16}$ and decreased immune response. ${ }^{17}$ Neurogenesis, formation of neuronal networks and synaptic connections are known to be formed in the initial phase of brain development, however the injury or insult that occurs in this phase may result in abnormality leading to manifestation of neurological diseases. ${ }^{18}$ Studies have also suggested neurotransmitter and morphological changes in neuronal cells played an important role in modulating neurobehavioral effects 
of $\mathrm{B}[\mathrm{a}] \mathrm{P} \cdot{ }^{19,20}$ Furthermore, $\mathrm{B}[\mathrm{a}] \mathrm{P}$ transplacentally can transfer from mother to foetus, causing in utero injury to the developing brain. $\mathrm{B}[\mathrm{a}] \mathrm{P}$ is able to penetrate the blood brain barrier ${ }^{4}$ and can modify the function of central nervous system. ${ }^{21}$ It is well established that environmental exposure to $\mathrm{B}[\mathrm{a}] \mathrm{P}$ can have multiple deleterious tissue effects depending on the dose, time (prenatal, postnatal) and term of exposure. ${ }^{2}$ Based on the above concerns, this study was carried out to investigate the low-dose exposure to $\mathrm{B}[\mathrm{a}] \mathrm{P}$ during pregnancy on neuronal morphology in hippocampus of young rats and learning and memory. We evaluated the effects of prenatal exposure to $\mathrm{B}[\mathrm{a}] \mathrm{P}$ on hippocampal morphology, because the hippocampus is a key area for learning and memory. Whereas, the link between direct gestational $\mathrm{B}[\mathrm{a}] \mathrm{P}$ exposure and its long lasting neurodegenerative potential on pre-adolescences offspring's subsequently causing learning and memory deficit and alteration in neuronal morphology in adult is yet to be addressed. Hence, our main objective of the present study is to provide some of the first evidence cementing a cause-and-effect relationship between the prenatal $\mathrm{B}[\mathrm{a}] \mathrm{P}$ exposure during gestation period and the hippocampal neuronal structure and behavioral dysfunction during adulthood.

\section{Materials and methods}

\section{Ethics statement}

All the protocols followed in the experiments were approved by the ethics committee of the institute (Ravenshaw University, Odisha, India) in accordance with the guidelines of the 'committee for the purpose of control and supervision of experiments on animals by Institutional Animal Ethics Committee (Regd. No.1927/Go/Re/S/16/ CPCSEA). Highest care was taken to reduce suffering of animals during sampling.

\section{Chemicals and reagents}

The investigative chemicals e.g. Benzo[a]pyrene including other standards used in these experiments were purchased from SigmaAldrich Chemicals (St. Louis, MO, USA) and Sisco Research Laboratories (SRL, India) unless otherwise mentioned.

\section{Experimental animals and treatment}

The experiments were carried out according to Ravenshaw University ethical guidelines for the care and use of laboratory animals. The pregnant Wistar rats were maintained in home cages at controlled temperature $\left(20-25^{\circ} \mathrm{C}\right)$ humidity and on a $12 \mathrm{hr}$ light $/ 12 \mathrm{hr}$ dark cycle with free access to food and water. $\mathrm{B}[\mathrm{a}] \mathrm{P}$ was then given during gestation thrice into the first 2 postnatal weeks; because rats are altricial, the postnatal exposure period corresponds to stages of brain development in the late second to third trimester human fetus, so that exposure encompasses brain development corresponding to the entire human fetal period. The rats were anesthetized and administration of B[a]P (i.p.) dose was carried out on (GD 14-17). Wistar rats were then separated into three experimental groups, with $(n=6)$ per group. Naïve (without any treatment), control (vehicle treated) received DMSO only and $\mathrm{B}[\mathrm{a}] \mathrm{P}$ treated $(300 \mu \mathrm{g} / \mathrm{kg} / \mathrm{BW} /$ day; each) three times on gestation (GD14) (the metamorphosing embryo stage) through (GD17) (the 1st fetal stage). The behavioural test was conducted began at PND 35 and continued to PND 42. The animals were sacrificed after behavioural testing and hippocampal region were snap frozen washed in normal saline, stored at $-80^{\circ} \mathrm{C}$ until further use.

\section{Behavioural tests}

\section{T-maze Test}

T-maze test was done in relevance to. ${ }^{22}$ It is made of acrylic material with two arms (left arm and right arm) also known as goal arm and a start arm. Two arms of the maze are $(50 \mathrm{~cm}$ long, $10 \mathrm{~cm}$ in width, with walls of $25 \mathrm{~cm}$ height) and the starting arm is $(70 \mathrm{~cm})$ separated by a acrylic partition. We used a positive reinforce (pellets) placed in right arm, so as to reward alternation behaviour. This appetitive motivated learning task was utilized to evaluate spatial working memory. ${ }^{23,24}$ This test is based on the willingness of rodents to explore a new environment, i.e. they prefer to visit a new arm of the maze rather than a familiar arm. Rats were habituated to the T-maze for 2-3 days. On $1^{\text {st }}$ day of habituation the rats were allowed to freely explore the maze for $5 \mathrm{~min}$. On $2^{\text {nd }}$ and $3^{\text {rd }}$ day pellets were placed as food reward in the left arm during training. Each test session rats were placed at the start arm then allowed to explore through the maze for 5 minutes. On Day 4 and Day 5 actual test was conducted with food deprivations. Between each consecutive test the maze was cleaned thoroughly with a $70 \%$ ethanol solution. The percentage of spontaneous alterations (number of turns in each goal arm), time spent in each arm and total trial duration the rat made was calculated and recorded using ANYMaze video-tracking system (Stoelting Co., USA) (Figure 1 \& Figure 2).

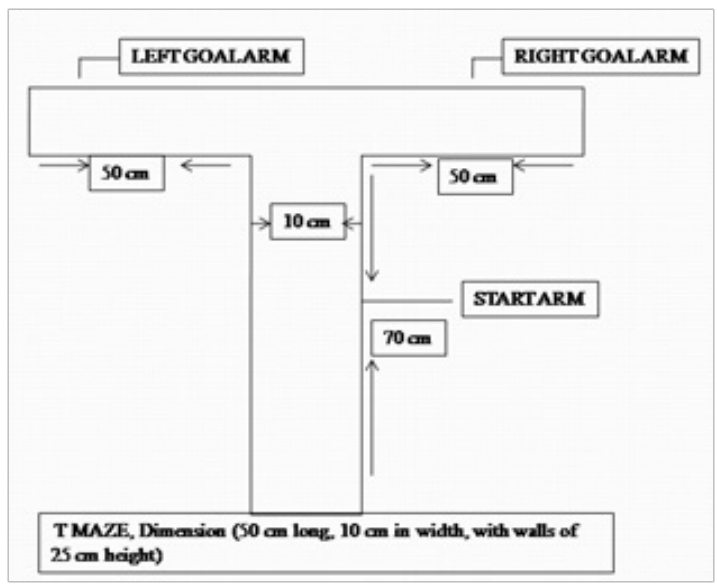

Figure I T-maze.

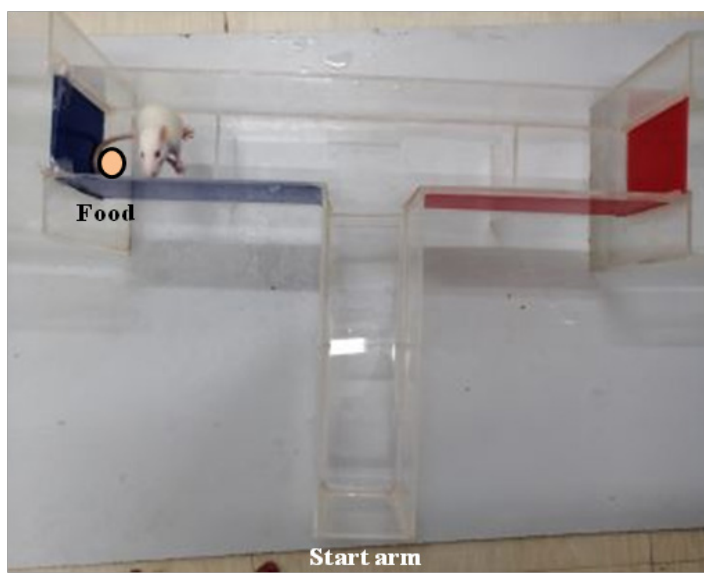

Figure 2 Performance of rat in T-maze. 


\section{Nobel object recognition test:}

The Novel object recognition test (NOR) evaluates the ability of rodents to recognize a novel object in the environment. To test for attention and memory in a low-motivational state recognition of a novel object was assessed. Tests were conducted in opaque plastic enclosures measuring $70 \times 41 \times 33 \mathrm{~cm}$. Objects consisted of plastic, glass, or ceramic material and were randomized for each animal. Animals were first habituated to the apparatus in 2 consecutive $5 \mathrm{~min}$ sessions over the course of 2 days. Testing began on day 3 with a 5 min 'information' session in which 2 identical objects (A/A) were placed in the cage for the animal to explore. The animal was then placed back in the enclosure with one object from the $\mathrm{A} / \mathrm{A}$ session and with another, dissimilar, 'novel' object (A/B session). The time spent actively exploring each object was recorded in video tracking using Any maze software (Stoelting Co., USA. After completion of each phase we were used $70 \%$ ethanol to clean the object and experimental apparatus (Figure 3).

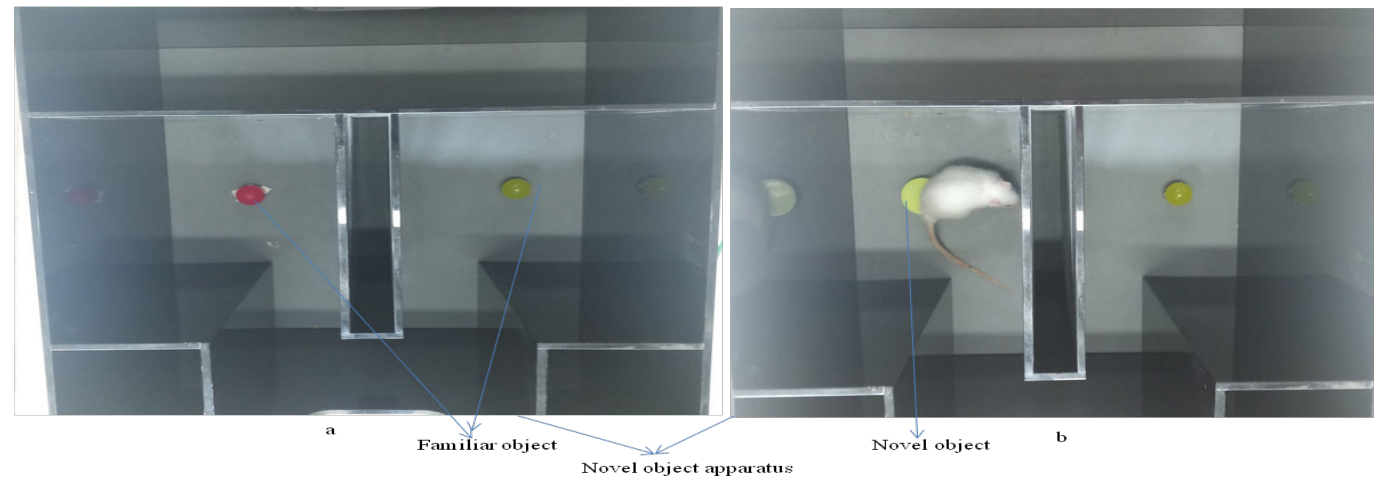

Figure 3 Novel object recognition setup.

\section{Histopathological study by H \& E staining}

Rats were sacrificed after the behavioral test all rats were anesthetized and perfused with $4 \%$ paraformaldehyde ${ }^{25}$ in $0.1 \mathrm{~mol} / \mathrm{L}$ phosphate buffer solution ( $\mathrm{pH}$ 7.4). Then, the brains were removed, dissected into hippocampal blocks and fixed in the similar solution for $24 \mathrm{~h}$ under running tap water, dehydrated in graded series of ethanol $(30-100 \%)$. Following routine processing in paraffin, serial coronal sections of the brain were cut at $8 \mu \mathrm{m}$ thickness in a rotary microtome (Leica, CM1520, Germany). The parts of each rat brain section were stained with Hematoxylin and Eosin (H\&E) stain. The slides were observed under microscope and measurement of the hippocampal area was performed and images were taken with requisite magnification with the help of Stereo microscope. The identification of neurons and glia were carried out as suggested previously. ${ }^{26}$ The neuronal cells in hippocampus of naïve, control and $\mathrm{B}[\mathrm{a}] \mathrm{P}$ groups were counted using dissecting microscope. ${ }^{27}$

\section{Statistical Analysis}

The mean and standard error of mean of each set, i.e., naive, control, B[a]P treated in DMSO $(<0.1 \%)$ were calculated. Statistical comparison was done among all the above mentioned groups. The post hoc analysis was done by Newman-Keul's test in all experimental groups wherever appropriate by using one way analysis of variance (ANOVA). Difference below the probability level $\mathrm{p}<0.05$ was considered statistically significant.

\section{Results}

\section{Behavioural test}

\section{$B[a] P$ impaired short term learning and memory:}

T-maze test was used to assess the learning and memory of $t$ wistar rats after $\mathrm{B}[\mathrm{a}] \mathrm{P}$ exposure during gestation. Track plots showing the position and movement of the Wistar at the centre of the object during the test recorded through video tracking indicating significant differences between control and treated groups [Figure 4(a)]. Our results showed significant increase in the time spent in left arm $\left(\mathrm{F}_{2.15}=30.03, \mathrm{p}<0.05\right)$, with decresed no of transitions $\left(\mathrm{F}_{2,15}=12.08\right.$, $\mathrm{p}<0.05)$, in $\mathrm{B}[\mathrm{a}] \mathrm{P}$ treated groups as compared to naive and control groups [Figure 4(b) \& Figure 4(c)]. Effects of prenatal B[a]P exposure on escape latency in rats and time spent in arms of T-Maze, at 6 week of age. $\mathrm{B}[\mathrm{a}] \mathrm{P}$-exposed rats learned significantly less in reaching left arm except for naïve and control. Values are means \pm SE $(n=6) .{ }^{*} p<$ $0.05 ;{ }^{* *} \mathrm{p}<0.01$ vs. control (repeated-measures Newman-Keul's test).

\section{Novel object recognition test}

Track plot showing preference for the novel object recognition evaluated as the difference between times spent with the novel versus the familiar object during the test through video tracking any maze software [Figure 5(a)]. The results showed a significant reduction in the time taken in exploring the novel object $\left(\mathrm{F}_{2,15}=22.78, \mathrm{p}<0.05\right)$, and increase in spontaneous exploration $\left(\mathrm{F}_{2,15}=16.98, \mathrm{p}<0.05\right)$ in $\mathrm{B}[\mathrm{a}] \mathrm{P}$ treated group when compared with naive \& control groups [Figure 5(b) \& Figure 5(c)]. The B[a]P treated groups reduced the preference for the novel object (main treatment effect, $* * p<0.01$ ), with significant effects for in comparison to naïve and control. There was no significant difference between naive and control groups, implicating that exposure to $\mathrm{B}[\mathrm{a}] \mathrm{P}$ impaired learning and memory of the offspring during later life.

\section{Histopathological study}

Histopathological analysis through haematoxylin and eosin ( $\mathrm{H} \& \mathrm{E})$ staining showed that there was a significant degeneration in the number of hippocampal neuron during early adolescences in the $\mathrm{B}[\mathrm{a}] \mathrm{P}$ treated group [Figure $6(\mathrm{c})]$ as compared to naive [Figure 6(a)], and control control [Figure 6(b)] group after intraperitonial administration of $\mathrm{B}[\mathrm{a}] \mathrm{P}(300 \mu \mathrm{g} / \mathrm{kg} / \mathrm{BW})$ during gestation $(\mathrm{n}=6)$ per group. The qualitative evaluation of images did not reveal gross alterations concerning cell bodies morphology or layer organization. Quantitative analysis was based on counting the number of neuron 
and glial cells in CA1 region of hippocampus (Image $\mathrm{J}$ software). In controls, both pyramidal and granular nerve cells were homogenous and a light distinct nucleus observed in hippocampus. Whereas after gestational administration of $\mathrm{B}[\mathrm{a}] \mathrm{P}$ during development period rats showed significantly higher neuronal loss when compared with

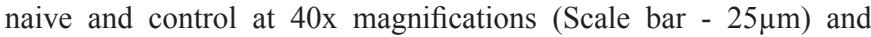
400x magnifications (Scale bar $-20 \mu \mathrm{m}$ ). Since the neurogenesis of hippocampal pyramidal neurons takes place between E17 and E19 in rats the reduction of neuronal cells in CA1 may indicate the effects of $\mathrm{B}[\mathrm{a}] \mathrm{P}$ administration on neuronal precursors, a highly susceptible cell type. Histogram representing evaluation of number of hippocampal neurons and glia showing a significant decreased in neuronal density with less number of pyramidal neuron $\left(\mathrm{F}_{2,15}=656.2, \mathrm{p}<0.05\right)$ and gliosis $\left(\mathrm{F}_{2,15}=1235, \mathrm{p}<0.05\right)$ in the of $\mathrm{B}[\mathrm{a}] \mathrm{P}$ treated group as compared to naive and control [Figure 6(d) Figure 6(e)] inducing alteration in number of neurons and glia of brain hippocampus.

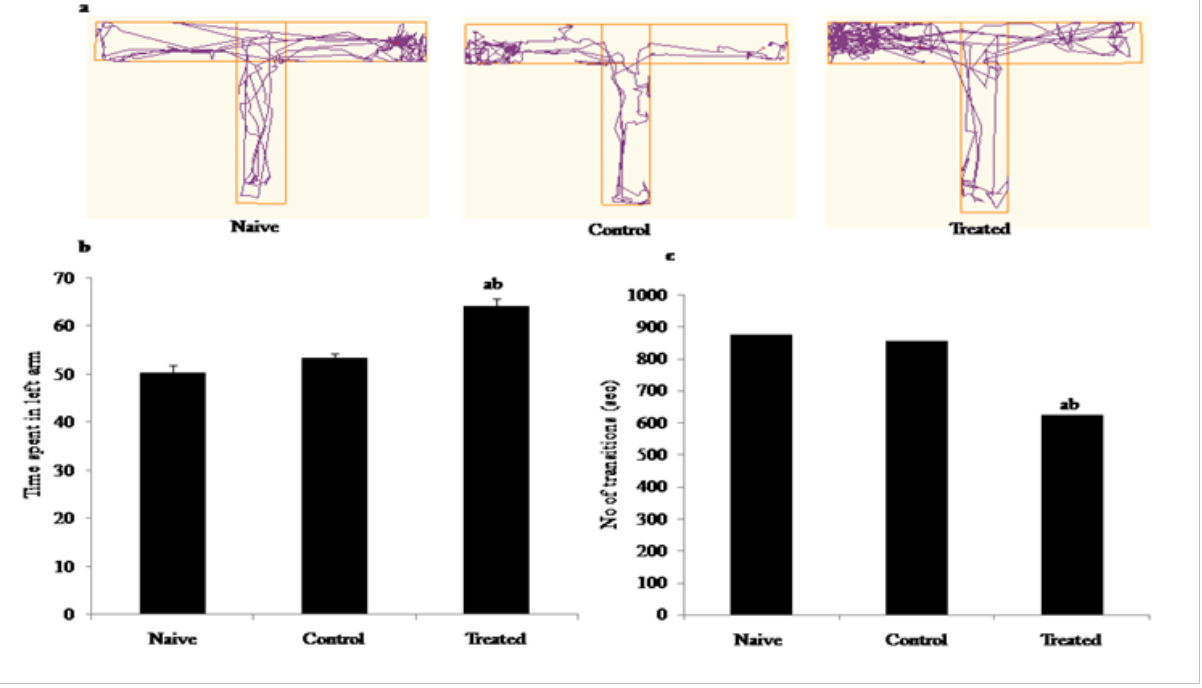

Figure 4 Behavioural studies: Effects of B[a]P after intraperitonial (i.p.) administration (300 $\mu \mathrm{g} / \mathrm{kg} / \mathrm{BW})$ to pregnant rats during early gestation and impact on learning and memory behavior of the pre adolescent offspring's during post natal development through T-maze test (a) Representation of track plot images (b) Time spent in left arm of the maze (sec), (c) No of transitions (sec) in naive, control (DMSO), B[a]P treated groups. Less number of transitions to the targeted left arm of T maze during the total test period ( 5 minutes) suggested the memory impairment. Values are expressed as mean \pm SEM, $n=6$. 'a' denotes $p<0.05$ when compared to naïve group, 'b' denotes $p<0.05$ when compared to control group.

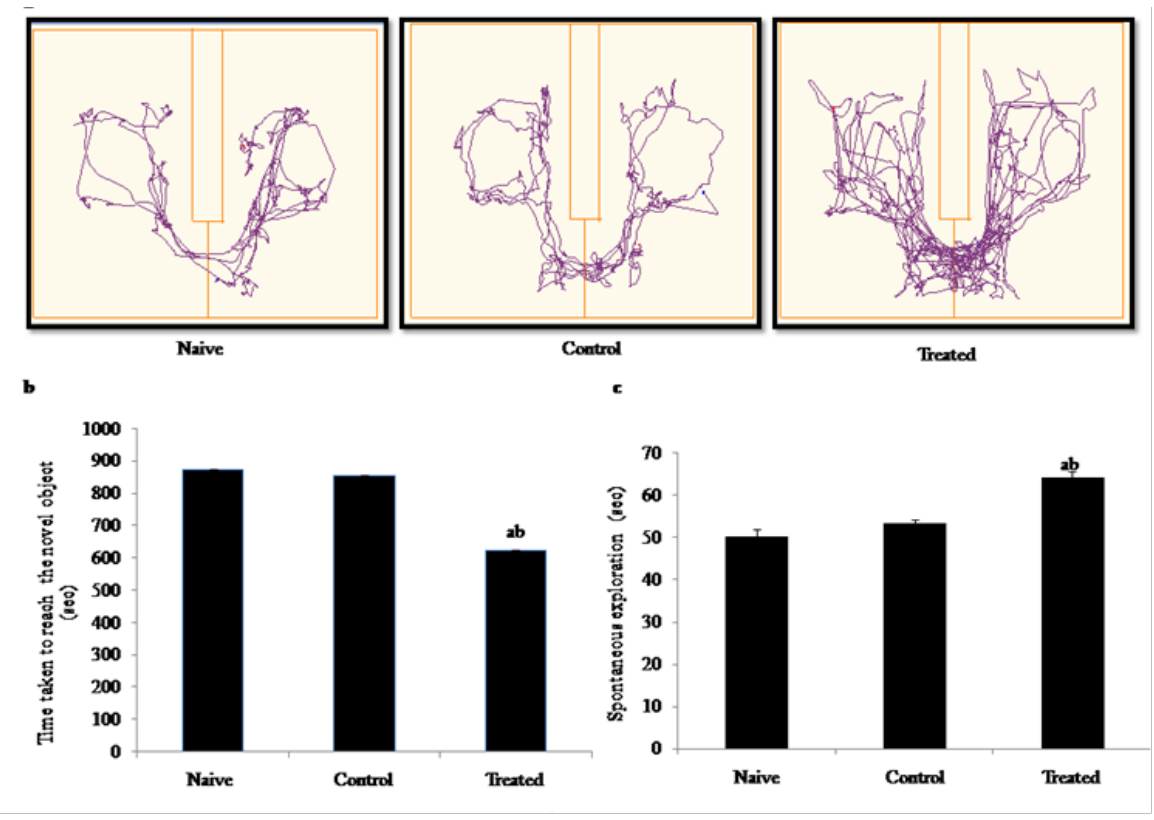

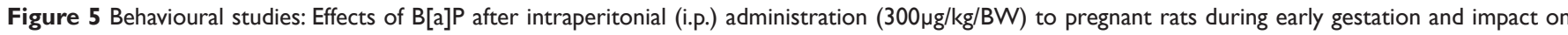
learning and memory behavior of the pre-adolescent offspring's during post natal development through Novel object recognition test (a) Track plot image representation (b) Time taken to explore the novel object (sec), (c) Spontaneous explorations through the maze (sec) in naive, control (DMSO), B[a]P treated groups. Explorative behaviors, such as sniffing the object or touching the object while looking at it, were considered as exploration of the objects. The time spent exploring the old or the novel object during the recognition phase was recorded. Values are expressed as mean \pm SEM, $n=6$. 'a' and 'b' denotes $p<0.05$ when compared to naïve and control group. 


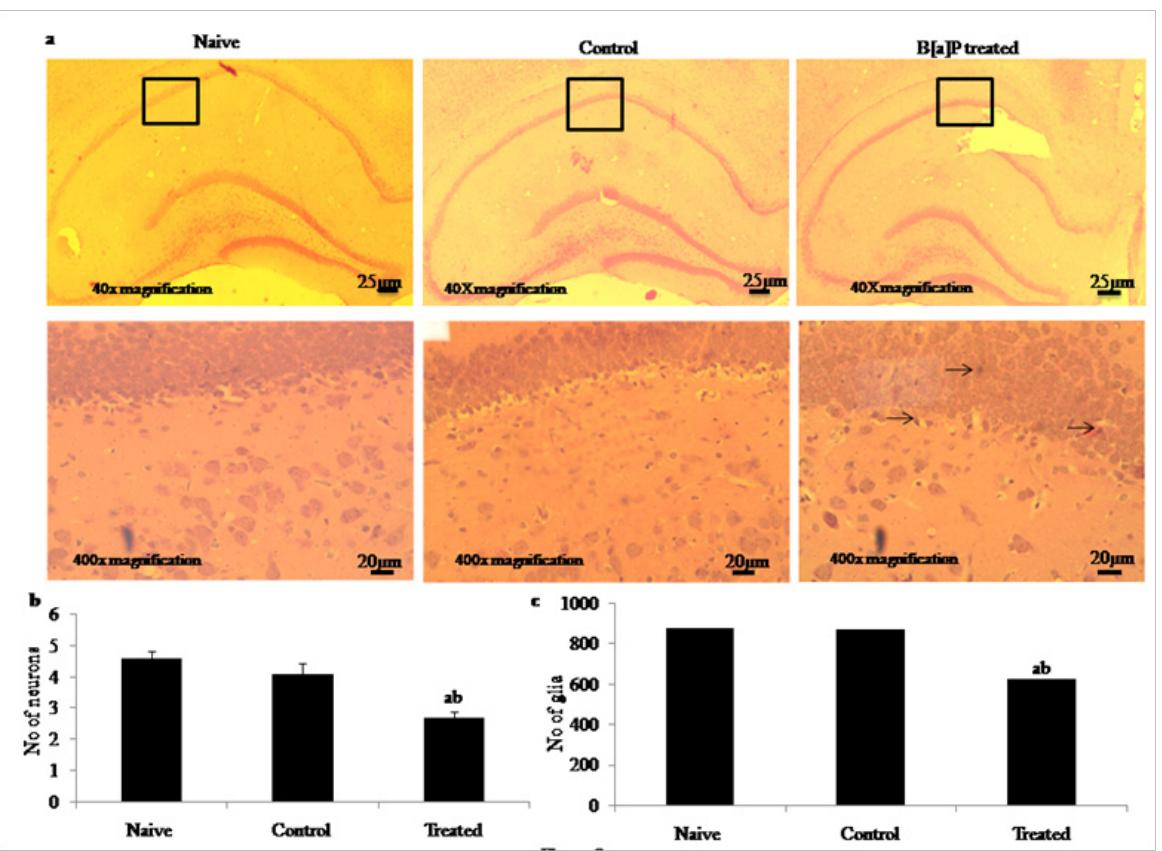

Figure 6 Effects of Benzo[a]pyrene after intraperitonial (i.p.) administration $(300 \mu g / \mathrm{kg} / \mathrm{BW})$ to pregnant rats during early gestation and impact on learning and memory behavior of the pre adolescent offspring's during post natal development through histopathological analysis by haematoxylin and eosin staining. Representative images of H\&E staining sections of offspring rat hippocampus in naïve [Figure 6(a)], control (DMSO) [Figure 6(b)] and B[a]P treated groups [Figure 6(c)] after intraperitonial administration of B[a]P during gestation (Scale bar $=25 \mu \mathrm{m}$ ) at $40 \mathrm{x}$ magnifications and (Scale bar $=20 \mu \mathrm{m})$ at $400 \mathrm{x}$ magnifications Histogram representing degeneration ( ) of hippocampal neurons [Figure 6(d)] and no of glia in hippocampus of B[a]P treated groups [Figure 6(e)] as compared to naive and control (<0.01\% DMSO) groups. Values are expressed as mean \pm SEM, $n=6$. 'a' and 'b' denotes $p<0.05$ when compared to naïve and control groups.

\section{Discussion}

We report in the present study that environmental exposure during pregnancy causes cognitive impairment in wistar rats. PAHs are predominantly anthropogenic in source and are liberated as a consequence of partial combustion carbon containing organic compounds. ${ }^{28} \mathrm{~B}[\mathrm{a}] \mathrm{P}$ is a prototype of PAHs family known to induce significant genotoxicity. Previous studies reported that prenatal exposure to $\mathrm{B}[\mathrm{a}] \mathrm{P}$ impairs the brain development and causes neurobehavioral response in later phase of life. ${ }^{11,29,30}$ Although different models of animal studies have been proposed to investigate the functional outcomes, it remains unclear whether gestational exposure to $\mathrm{B}[\mathrm{a}] \mathrm{P}$, alter the brain structure and function at an early adolescences and adult stages with the underlying hippocampal neuromorphology. Evidences Epidemiological from human studies has shown prenatal exposure of $\mathrm{B}[\mathrm{a}] \mathrm{P}$ to pregnant women affects foetal cognitive development adversely, resulting in low birth weight and reduced head circumference, as well as impaired learning and memory in the offspring. ${ }^{14}$

Hence, the main objective of the present study was to elucidate the intraperitonial administration of $\mathrm{B}[\mathrm{a}] \mathrm{P}$ during gestation to Wistar rats and its association with altered behavioural phenotypes and neuronal morphology during post natal developmental period. Our present study suggests intraperitonial exposure to $\mathrm{B}[\mathrm{a}] \mathrm{P}$ during early gestation causes spontaneous alteration in learning and memory through T-maze test. Findings of our present study is in support with, ${ }^{8}$ where sub-acute exposure to two lowest doses of $\mathrm{B}[\mathrm{a}] \mathrm{P}(0.02$ and 0.2 $\mathrm{mg} / \mathrm{kg}$ ) showed a learning disability in a Y-maze test. Gestational exposure to a mixture of environmental pollutants, including $\mathrm{B}[\mathrm{a}]$ $\mathrm{P}$ induced a long-term deficit in learning affecting behavioural performance by altering central neurotransmission. ${ }^{11}$ In utero $\mathrm{B}[\mathrm{a}]$ $\mathrm{P}$ exposure was found to impair the function of the somatic sensory cortex of the offspring of exposed-dams leading to cognitive deficits, drug addiction and psychiatric disorders. ${ }^{5}$ Similarly, chronic $\mathrm{B}[\mathrm{a}]$ $\mathrm{P}$ exposure, found that a $\mathrm{B}[\mathrm{a}] \mathrm{P}$ dose of $6.25 \mathrm{mg} / \mathrm{kg}$ significantly impacted learning and memory. ${ }^{31}$ The results of our present study confirmed object location memory dysfunction of the pre-adolescent offspring's through Novel object recognition test leading to significant loss of memory and behavioural performances. Similarly, previous studies reported that In utero exposure to $\mathrm{B}[\mathrm{a}] \mathrm{P}$ aerosol- causes significant learning and memory impairment in offspring in an object discrimination paradigm. ${ }^{30}$ It was suggested that $\mathrm{B}[\mathrm{a}] \mathrm{P}$ induces significant breakdown of homeostatic cellular mechanisms expressing structural and physiological changes thereby modulating emotional response, learning and memory.

Learning and memory deficits have been also associated with increased hippocampal neurogenesis, while gestational exposure to $\mathrm{B}[\mathrm{a}] \mathrm{P}$ (GD 14-17) on hippocampus might provide evidence regarding the negative effect on hippocampal neurogenesis. The developmental processes such as differentiation, neurogenesis and synaptogenesis are incomplete and progressive in nature at early stages of life. Hence, it is important to study the mechanism of irreparable loss induced by $\mathrm{B}[\mathrm{a}] \mathrm{P}$ during postnatal period. As developing foetal brain progresses through a rapid phase of development it is considered as the most critical and susceptible period of exposure to genotoxic compounds. Our present study demonstrated significant reduction of hippocampal neurons and glial cells through histopathological observation after exposure to $\mathrm{B}[\mathrm{a}] \mathrm{P}$ at early gestation. Moreover, the decreased neuronal cell number in the conus ammonis (CA) region might be due to ROS induced necrotic cell death and the findings are in agreement 
with our study. ${ }^{32}$ Similarly, intracisternal $\mathrm{B}[\mathrm{a}] \mathrm{P}$ administration to rat neonates leads to significant decrease in hippocampal neuronal and glial cell counts when compared with control group. ${ }^{33}$ Previous study also reported that an increase in lipid peroxidation level in response to $\mathrm{B}[\mathrm{a}] \mathrm{P}$ exposure suggests damage to neuronal cell membrane thus leading to impaired cell signalling. ${ }^{3}$ The possible neurodegenerative consequences following $\mathrm{B}[\mathrm{a}] \mathrm{P}$ administration at GD14-17 and its neurobehavioral manifestation in pre-adolescent offspring's may be associated with altered neuronal morphology. The results of the present study suggest that exposure to $\mathrm{B}[\mathrm{a}] \mathrm{P}$ at early gestation causes learning and memory deficit in offspring rats affecting the neuronal survival in their later-life suggesting to establish strategies to reduce the impact of gestational exposure to $\mathrm{B}[\mathrm{a}] \mathrm{P}$ on learning and memory in humans.

\section{Conclusion}

In conclusion our findings states the prenatal $\mathrm{B}[\mathrm{a}] \mathrm{P}$ exposures are able to impact hippocampal morphogenesis and the outcomes may be verified along postnatal development, persist throughout adolescence and even into adulthood. The preset study suggest that in utero exposure to $\mathrm{B}[\mathrm{a}] \mathrm{P}$ during gestation (e.g. pre weaning) affects the neuronal structure reducing the number of differentiated neurons and glial population significantly. These morphological changes depict the behavioural alterations that result in deficits in learning and memory during adulthood. However, our study emphasize that further research are needed to know the real cellular and molecular mechanism to determine whether neuronal loss plays a role in the altered learning and memory behavior in adult rats after in utero exposue to $\mathrm{B}[\mathrm{a}] \mathrm{P}$.

\section{Acknowledgments}

This study was supported by research grant to MP from (BRNS, Mumbai, 37(1)/14/27/2015/BRNS), Department of Science and Technology (DST), Odisha, (2762800402014/20/665) and DRDO, New Delhi DG(TM)/81(48222/LSRB-294/PEE \& BS/2017) The funds supported to Lipsa Das (UGC-RGNF National Fellow-RGNF2015-17-SC-ORI-10772) awarded by University Grant Commission (UGC), Govt. of India.

\section{Conflicts of interest}

The authors declare that they have no conflicts of interest.

\section{References}

1. Jacobson L, Jacobson SW. Intellectual impairment in children exposed to polychlorinated biphenyls in utero. $N$ Engl J Med. 1996;335(11):783-789.

2. Ramesh A, Archibong AE, Hood DB, et al. Global environmental distribution and human health effects of polycyclic aromatic hydrocarbons. CRC Press; Boca Raton: 2011;95-124.

3. Saunders CR, Das SK, Ramesh A, et al. Benzo [a]pyrene-induced acute neurotoxicity in the F-344 rat: role of oxidative stress. $J$ Appl Toxicol. 2006;26(5):427-438.

4. Das M, Mukhtar H, Seth P. Distribution of benzo(a) pyrene in discrete region of the rat brain. Bull Environ Contam Toxicol. 1985;35(4):500-504.

5. Grova N, Schroeder H, Farinelle S, et al. Sub-acute administration of benzo[a]pyrene $(\mathrm{B}[\mathrm{a}] \mathrm{P})$ reduces anxiety-related behaviour in adult mice and modulates regional expression of N-methyl-D-aspartate (NMDA) receptors genes in relevant brain regions. Chemosphere. 2008;73(supply 1):295-302.
6. Moir D, Viau A, Chu I, et al. Pharmacokinetics of Benzo[a]pyrene in the rat. J Toxicol Environ Health A. 1998;53(7):507-530.

7. Potvin O, Allen K, Thibaudeau G, et al. Performance on Spatial Working Memory Tasks After Dorsal or Ventral Hippocampal Lesions and Adjacent Damage to the Subiculum. Behav Neurosci. 2006;120(2):413-422.

8. Grova N, Valley A, Turner JD, et al. Modulation of behaviour and NMDA-R1 gene mRNA expression in adult female mice after sub-acute administration of benzo(a)pyrene. Neurotoxicology. 2007;28(3):630-636.

9. Otto D, Skalik I, Bahboh R, et al. Neurobehavioral performance of Czech school children born in years of maximal air pollution (1982-1983). Neurotoxicology. 1997;18(3):903-910.

10. Majachrzak R, Sroczynski J, Chelmeska E. Evaluation of the nervous system in workers in the furnace and coal divisions of the coke-producing plants. Med Pr. 1990;41(2):108-113.

11. Wormley DD, Ramesh A, Hood DB. Environmental contaminant-mixture effects on CNS development, plasticity, and behaviour. Toxicol Appl Pharmacol. 2004;197(1):49-65.

12. Perera FP, Whyatt RM, Jedrychowski W, et al. Recent developments in molecular epidemiology: A study of the effects of environmental polycyclic aromatic hydrocarbons on birth outcomes in Poland. Am J Epidemiol. 1998;147(3):309-314.

13. Perera FP, Jedrychowski W, Rauh V, et al. Molecular epidemiologic research on the effects of environmental pollutants on the fetus. Environ Health Perspect. 1999;107(Suppl 3):451-460.

14. Perera FP, Rauh V, Tsai WY, et al. Effects of transplacental exposure to environmental pollutants on birth outcomes in a multiethnic population. Environ Health Perspect. 2003;111(2):201-205.

15. Perera FP, Tang D, Rauh V, et al. Relationship between polycyclic aromatic hydrocarbon-DNA adducts, environmental tobacco smoke, and child development in the World Trade Center cohort. Environ Health Perspect. 2007;115(10):1497-1502.

16. Perera FP, Li Z, Whyatt R, et al. Prenatal airborne polycyclic aromatic hydrocarbon exposure and child IQ at age 5 years. Pediatrics. 2009;124(2):195-202.

17. Hannah JB, Hose JE, Landolt ML, et al. Benzo(a)pyrene-induced morphologic and developmental abnormalities in rainbow trout. Arch Environ Contam Toxicol. 1982;11(6):727-734.

18. Bondy SC, Campbell A. Mini-review: developmental toxicology. $J$ Neurosci. 2005;81:605-612.

19. Zhang HM, Nie JS, Xue CE, et al. Influence of Benzo[a]pyrene on learning and memory and content of amino acid neurotransmitter in hippocampus of rats. Zhonghua Lao Dong Wei Sheng Zhi Ye Bing Za Zhi. 2008;26(9):546-548.

20. Niu Q, Zhang H, Li X, et al. Benzo[a]pyrene induced neurobehavioral function and neurotransmitter alterations in coke oven workers. Occup Environ Med. 2010;67(7):444-448.

21. Konstandi M, Pappas P, Jhonson E, et al. Suppression of acquisition of conditioned avoidance behavior in the rat by 3-methyl-choanthrane. Pharmacol Biochem Behav. 1997;56:637-641.

22. Robert MJ Deacon, J Nicholas P Rawlins. T-maze alternation in the rodent. Nat Protoc. 2006;1(1):7-12.

23. Fanelli RJ, Burright RG, Donovick PJ. A multivariate approach to the analysis of genetic and septal lesion effects on maze performance in mice. Behav Neurosci. 1983;97(3):354-369.

24. Schlesinger K, Pelleymounter MA, van de Kamp J, et al. Substance P 
facilitation of memory: effects in an appetitively motivated learning task. Behav Neural Biol. 1986;45(2):230-239.

25. Davenport D, Camougis G, Hickock JF. Analyses of the behavior of commensals in host factor. I. A hesionid polychaete and a pinnotherid crab. Anim Behav. 1960;8(3-4):209-218.

26. Garman RH. Histology of the central nervous system. Toxicol Pathol. 2011;39(1):22-35.

27. Ranjan A, Behari J, Mallick BN. Cytomorphometric changes in hippocampal CA1 neurons exposed to simulated microgravity using rats as model. Front Neurol. 2014;5:77.

28. Patri M, Singh A, Mallick BN. Protective role of noradrenaline in benzo[a] pyrene-induced learning impairment in developing rat. $J$ Neurosci. 2013;91(11):1450-1462.

29. Sheng L, Ding X, Ferguson M, et al. Prenatal polycyclic aromatic hydrocarbon exposure leads to behavioral deficits and downregulation of receptor tyrosine kinase, MET. Toxicol Sci. 2010;118(2):625-634.
30. Li Z, Chadalapaka G, Ramesh A, et al. PAH particles perturb prenatal processes and phenotypes: protection from deficits in object discrimination afforded by dampening of brain oxidoreductase following in utero exposure to inhaled benzo(a) pyrene. Toxicol Sci. 2012;125(1):233-247.

31. Xia Y, Cheng S, He J, et al. Effects of subchronic exposure to benzo[a] pyrene $(\mathrm{B}[\mathrm{a}] \mathrm{P})$ on learning and memory, and neurotransmitters in male Sprague-Dawley rat. Neurotoxicology. 2011;32(2):188-198.

32. Adedara IA, Owoeye O, Aiyegbusi MA, et al. Kolaviron protects against benzo[a]pyrene-induced functional alterations along the brain-pituitarygonadal axis in male rats. Environ Toxicol Pharmacol. 2015;40(2):459470 .

33. Patel B, Das SK, Das S, et al. Neonatal exposure to Benzo[a]pyrene induces oxidative stress causing altered hippocampal cytomorphometry and behaviour during early adolescence period of male Wistar rats. Int $J$ Dev Neurosci. 2016;50:7-15. 